\title{
Adrenal insufficiency and bilateral adrenal enlargement: demonstration by computed tomography
}

\author{
T. Wheatley, S. Gallagher ${ }^{1}$, A.K. Dixon ${ }^{1}$ \\ Departments of Medicine and 'Radiology, Addenbrooke's Hospital, Hills Road, Cambridge CB2 2QQ, UK.
}

\begin{abstract}
Summary: A patient presented with fever, malaise and a staphylococcal wound infection occurring 3 weeks after severe haemorrhage from a lacerated brachial artery. There were no clinical features to suggest Addison's disease but abdominal computed tomography to exclude abdominal sepsis showed bilateral adrenal gland enlargement with preservation of adrenal shape. This was consistent with resolving adrenal haemorrhage or infarction and endocrinological investigations confirmed primary adrenal failure.
\end{abstract}

\section{Introduction}

Primary adrenocortical insufficiency is often overlooked because the presenting features, such as malaise, abdominal pain, weight loss and gastro-intestinal symptoms are non-specific and may be misleading (Bayliss, 1980; Irvine et al., 1979). We report the early diagnosis of adrenal failure following the observation of adrenal enlargement on computed tomography (CT) performed while investigating pyrexia and abdominal pain.

\section{Case report}

A previously fit 39 year old English man was admitted with a severe laceration around the right elbow caused by broken glass. There was no past history of renal or pulmonary tuberculosis, or travel to the tropics or North America and no family history of auto-immune disease or tuberculosis. On examination he was pale and sweating with substantial arterial bleeding from the right brachial artery, a sinus tachycardia of 120 beats/min and a supine left brachial blood pressure of $80 / 50 \mathrm{mmHg}$. There was no pigmentation suggestive of Addison's disease nor clinical features of other auto-immune diseases or a generalized bleeding disorder. Initial investigations showed a normal chest radiograph, plasma sodium $135 \mathrm{nmol} / 1$, plasma potassium $3.6 \mathrm{nmol} / 1$, plasma bicarbonate $27 \mathrm{mmol} / 1$, plasma urea $3 \mathrm{mmol} / \mathrm{l}$ and plasma creatinine $90 \mu \mathrm{mol} / 1$. Following treatment with 1.51 of Haemocell, his systemic blood pressure rose to $130 /$

Correspondence: T. Wheatley, M.A., M.R.C.P.

Accepted: 15 August 1984
$85 \mathrm{mmHg}$ and emergency exploration of the right ante-cubital fossa was performed. During the operation he received 3 units of whole blood and his systolic blood pressure varied between 100 and $140 \mathrm{mmHg}$. His post-operative recovery was uncomplicated.

Eleven days later he was readmitted with abdominal pain, weight loss, pyrexia and a wound infection from which Staphylococcus aureus was isolated. His right brachial blood pressure was $150 / 75 \mathrm{mmHg}$ and further investigations showed a normal chest radiograph, normal plasma electrolytes, a normochromic normocytic anaemia of $10.6 \mathrm{~g} / \mathrm{dl}$, a normal platelet count, normal clotting studies and sterile blood cultures. He was treated with $500 \mathrm{mg}$ flucloxacillin every $6 \mathrm{~h}$ but, as his abdominal pain and pyrexia persisted, abdominal CT examination was performed which showed marked bilateral adrenal enlargement (Figure 1). The CT findings led to endocrinological investigations which showed primary adrenocortical insufficiency. A 9 a.m. basal plasma adrenocorticotrophic hormone (ACTH) concentration was elevated at $270 \mathrm{ng} / 1$ (normal range less than $10-80 \mathrm{ng} / \mathrm{l}$ ) and a low 9 a.m. plasma cortisol concentration of $120 \mathrm{nmol} / 1$ (normal greater than $250 \mathrm{nmol} / \mathrm{l}$ ) rose only to $130 \mathrm{nmol} / 1$ $30 \mathrm{~min}$ after the intramuscular administration of $250 \mu \mathrm{g}$ of tetracosactrin (Synacthen). Primary adrenocortical insufficiency was confirmed by a 9 a.m. plasma cortisol concentration of $160 \mathrm{nmol} / 1$ following the intramuscular administration of $1 \mathrm{mg}$ of tetracosactrin acetate and zinc complex (Synacthen depot) for $3 \mathrm{~d}$. Screening for adrenal, thyroid and gastric parietal cell antibodies was negative. A repeat high resolution CT examination of the adrenals 3 weeks later showed little overall change in size. However, after intravenous contrast enhancement 


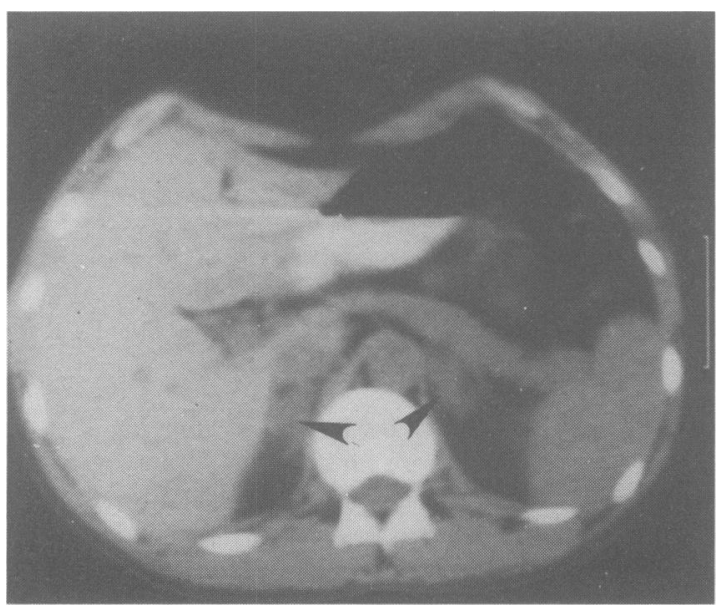

Figure 1 Abdominal CT showing enlarged adrenals (arrows) which still retain an adrenal shape.

( $50 \mathrm{ml}$ of sodium iothalamate, Conray 420$)$, each adrenal gland showed rim enhancement with a fluid dense centre (Figure 2). A third scan after 8 weeks showed some diminution in adrenal size but no evidence of developing calcification. Following treatment with hydrocortisone and 9-alpha-fludrocortisone the patient's abdominal pain, pyrexia and malaise resolved and 3 months later while taking

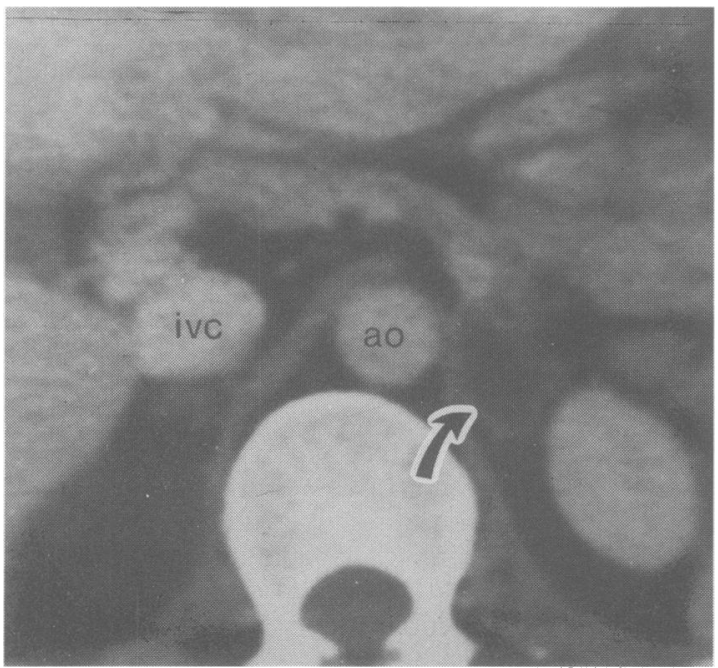

Figure 2 High resolution post-intravenous contrast CT scan of the left adrenal gland at 3 weeks. The adrenal (arrow) is still enlarged. The appearance of rim enhancement around an avascular centre is consistent with either infarction or resolving haemorrhage. ivc: inferior vena cava; ao: aorta. hydrocortisone $20 \mathrm{mg}$ in the morning and $10 \mathrm{mg}$ in the evening and $0.1 \mathrm{mg} / \mathrm{d}$ 9-alpha-fludrocortisone, he re-ڤ mained asymptomatic with a normal chest radiograph and plasma electrolytes.

\section{Discussion}

Although it is well known that adrenocortical insuf- $\frac{\bar{c}}{\overline{0}}$ ficiency may follow local sepsis, septicaemia and $\vec{\nabla}$

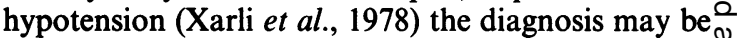
overlooked until an adrenal crisis occurs (Portnay $e t^{\infty}$ al., 1974; Bayliss, 1980), since if acute adrenal failure is $\vec{O}$ superimposed upon previously normal adrenal func- $\overrightarrow{-}$ tion, the typical features of chronic anorexia, weight $\bar{\sigma}_{\sigma}$ loss and pigmentation are absent (Bayliss, 1980). Inס our case neither the clinical signs nor plasma elec- $\frac{0}{3}$ trolytes suggested the diagnosis of adrenal failure while the presenting symptoms initially seemed adequately explained by concurrent staphylococcal in- $-\vec{O}$ fection, so that adrenocortical insufficiency was discovered only after an adrenal abnormality had been $\omega^{\omega}$ demonstrated by CT.

The adrenal glands can be visualized by $\mathrm{CT}$ in $\mathrm{a} \rightarrow$ majority of patients (Brownlie \& Kreel 1978; Mon-3 tagne et al., 1978) and several authors have stressed its value in the diagnosis of primary and secondary $\vec{\omega}$ adrenal tumours and Cushing's syndrome due goo pituitary disease or ectopic adrenocorticotrophic hofmone secreting neoplasms (Dunnick et al., 19得; White et al., 1982; Adams et al., 1983). CT has beêt less useful in the diagnosis of Addison's disease and although small gland remnants and adrenal calcifica- $\frac{\circ}{\circ}$ tion may be seen (Doppman et al., 1982; Huebener \& $\varrho$ Treugut, 1984) others have reported normal $\overrightarrow{\overrightarrow{0}}$ appearance of adrenal glands in primary adrenal 3 failure (Korobkin et al., 1979; Eghrari et al., 1980; Adams et al., 1983). However, when adrenal failure has been due either to granulomatous infiltration $\frac{\text { 을 }}{3}$ caused by tuberculosis (Wilms et al., 1983), histoplasmosis (Doppman et al., 1982; Wilson et al., 1984) or $\frac{3}{3}$ blastomycosis (Halvorsen et al., 1982) or to acute adrenal haemorrhage and infarction, the CT findings $\frac{}{\beta}$ of bilateral enlargement have contributed to the diagnosis and management.

Korobkin et al. (1979) was the first to describe the $\frac{7}{0}$ association of primary adrenal failure and CT appearances suggestive of adrenal haemorrhage and $\mathcal{N}^{N}$ infarction. Subsequently other reports have shown $N$ similar findings in patients with haemorrhagic tenden- $N$ cies due either to therapeutic anticoagulation (Swift $e t^{\mathrm{\omega}}$ al., 1981; Liu et al., 1982; Ling, 1983) or thrombocytopenia in patients with myeloproliferative dis- 0 ease (Albert et al., 1982; Wolverson \& Kannegiesser, $\mathbb{D}^{\circ}$ 1984). As the occurrence of adrenal haemorrhage in $\cdot$ this group is well known (Portnay et al., 1974), it ${ }_{0}^{\circ}$ should always be considered when such patients $\vec{D}$ 
present with abdominal pain, nausea, vomiting, pyrexia or hypotension.

However, even when clotting and platelet function are normal, bilateral adrenal haemorrhage may follow an episode of hypotension or infection (Xarli et al., 1978). Such patients are at particular risk since concurrent injury or infection may provide an adequate explanation of their symptoms, delaying the diagnosis of adrenal failure until an Addisonian crisis occurs. However, these patients may well have CT examinations of the abdomen and Wolverson \& Kannegiesser (1984) reported 2 patients in whom adrenal haemorrhage was noted on CT examination performed to exclude a sub-phrenic abscess complicating pneumonia. In our patient the CT appearances were compatible with either adrenal infarction or resolving haemorrhage, as the non-enhancing central portion would be compatible with an area either of resolving haematoma, or oedematous infarcted tissue.

Both hypotension and infection with S.aureus have been associated with adrenal haemorrhage and infarction found post-mortem (Xarli et al., 1978) and while the exact patho-physiology is uncertain, in the absence of a systemic haemorrhagic disorder, the important factors are probably the vascular supply to the gland and the extent of recent adrenocortical stimulation. The adrenal glands are intensely vascular structures with extensive small arterial branching but venous drainage often limitat to one vessel (Anson et al., 1947). This not only predisposes to haemorrhage and infarction, but facilitates the one leading to the other, so that the initial cause may be hard to determine (Berte, 1953). The role of recent adrenocortical stimulation is important and relevant to our patient in whom staphylococcal infection occurred following the stress of previous trauma and substantial blood loss. The administration of bacterial endotoxin to rats causes an increase in adrenal size and weight, but not haemorrhage. However, if these animals are previously stressed, or pre-treated with adrencorticotrophic hormone, the administration of endotoxin, which may be concentrated in the adrenal cortex (Jones \& Carter, 1955), causes adrenal haemorrhage (Levin \& Cluff, 1965; Beisel \& Rapoport, 1969).

Now that CT of the abdomen is becoming more commonplace, bilaterally enlarged adrenal glands will be shown as an incidental finding in numerous patients. This will usually be due to metastatic disease which should be recognisable by loss of the normal adrenal shape, while pituitary and ectopic ACTH secreting tumours should be considered when the adrenal shape is well preserved. However, sometimes the adrenal glands will be enlarged due to adrenal infarction and/or resolving haemorrhage which may lead on to primary adrenal failure. If in these circumstances adrenal insufficiency is considered and excluded by performing a short tetracosactrin test, progression to a life threatening Addisonian crisis may be avoided.

\section{Acknowledgements}

We thank Dr D. Rubenstein for permission to report this case, Professor R. Y. Calne for the initial referral and Mrs L. Stellitano and Mrs M. Watts for typing the manuscript.

\section{References}

ADAMS, J.E., JOHNSON, R.J., RICKARDS, D. \& ISHERWOOD, I. (1983). Computed tomography in adrenal disease. Clinical Radiology, 34, 39.

ALBERT, S.G., WOLVERSON, M.K. \& JOHNSON, F.E. (1982). Bilateral adrenal haemorrhage in an adult. Demonstration by computed tomography, Journal of the American Medical Association, 247, 1737.

ANSON, B.J., CAULDWELL, E.W., PICK, J.W. et al. (1947). The blood supply of the kidneys, supra-renal gland and associated structures. Surgery, Gynecology \& Obstetrics, 84, 313.

BAYLISS, R.I.S. (1980). Adrenal cortex. Clinics in Endocrinology and Metabolism, 9, 477.

BEISEL, W.R. \& RAPOPORT, M.I. (1969). Inter-relations between adrencortical functions and infectious illness, New England Journal of Medicine, 280, 541.

BERTE, S.J. (1953). Spontaneous adrenal haemorrhage in the adult: literature review and report of two cases. Annals of Internal Medicine, 38, 28.

BROWNLIE, K. \& KREEL, L. (1978). Computer assisted tomography of normal supra-renal glands. Journal of Computer Assisted Tomography, 2, 1.

DOPPMAN, J.L., GILL, J.R., NIENHUIS, A.W., EARLL, J.M. \& LONG, J.A. (1982). CT findings in Addison's disease. Journal of Computer Assisted Tomography, 6, 757.

DUNNICK, N.R., SCHANER, E.G., DOPPMAN, J.L., STROTT, C.A., GILL, J.R. \& JAVADPOUR, N. (1979). Computed tomography in adrenal tumours. American Journal of Roentgenology, 132, 43.

EGHRARI, M., MCLOUGHLIN, M.J., ROSEN, I.E., ST. LOUIS, E.J., WILSON, S.R., WISE, D.J.\& YEUNG, H.P.H. (1980). The role of computed tomography in assessment of tumoral pathology of the adrenal glands. Journal of Computer Assisted Tomography, 4, 71.

HALVORSEN, R.A. JR., HEASTON, D.K., JOHNSTON, W.W., ASHTON, P.R., \& BURTON, G.M. (1982). Case report. CT guided thin needle aspiration of adrenal bastomycosis, Journal of Computer Assisted Tomography, 6, 389.

HUEBENER, K.-H. \& TREUGUT, H. (1984). Adrenal cortex dysfunction: CT findings. Radiology, 150, 195. 
IRVINE, W.J., TOFT, A.D. \& FEEK, C.M. (1979). Addison's disease. In The Adrenal Gland, p. 134, Raven Press, New York.

JONES, R.S. \& CARTER, Y. (1955). Incorporation in adrenal cortex of $\mathrm{C}^{14}$ labelled fractions of Klebsiella pneumoniae. Proceedings of Society of Experimental Biology and Medicine, 90, 148.

KOROBKIN, M., WHITE, E.A., KRESSEL, H.Y., MOSS, A.A. \& MONTAGNE, J.P. (1979). Computed tomography in the diagnosis of adrenal disease. American Journal of Roentgenology, 132, 231.

LEVIN, J. \& CLUFF, L.E. (1965). Endotoxaemia and adrenal haemorrhage. Journal of Experimental Medicine, 121, 247.

LING, D., KOROBKIN, M., SILVERMAN, P.M. \& DUNNICK, N.R. (1983). CT demonstration of bilateral adrenal haemorrhage. American Journal of Roentgenology, 141, 307.

LIU, L., HASKIN, M.E., ROSE, L.I. \& BEMIS, C.E. (1982). Diagnosis of bilateral adrencortical haemorrhage by computed tomography, Annals of Internal Medicine, 97, 720.

MONTAGNE, J.P., KRESSEL, H.Y., KOROBKIN, M. \& MOSS, A.A. (1978). Computed tomography of the normal adrenal glands. American Journal of Roentgenology, 130, 963.

PORTNAY, G.I., VAGENAKIS, A.G. \& BRAVERMAN, L.E.
(1974). Anticoagulant therapy and acute adrenal insufficiency. Annals of Internal Medicine, 81, 115.

SWIFT, D.E., OVERHOLD, E.L. \& TRAVELLI, R. (1981). Methods of diagnosis of acute adrenal haemorrhage complicating anticoagulant therapy - abdominal CAT scanning. Wisconsin Medical Journal, 80, 25.

WHITE, F.E., WHITE, M.C., DRURY, P.L., KELSEY FRY, I. \& $\overline{\overline{\bar{c}}}$ BESSER, G.M. (1982). Value of computed tomography of 0 the abdomen and chest in investigation of Cushing's syndrome, British Medical Journal, 284, 771.

WILMS, G.E., BAERT, A.L., KINT, E.J., PRINGOT, J.H. \& GODDEERIS, P.G. (1983). Computed tomographic find- $\Omega$ ings in bilateral adrenal tuberculosis, Radiology, 146, 729. ڤొ

WILSON, D.A., MUCHMORE, H.G., GOEN TISDAL, R., $\vec{\circ}$ FAHMY, A. \& PITHA, J.V. (1984). Histoplasmosis of the : adrenal glands studied by CT. Radiology, 150, 779.

WOLVERSON, M.K. \& KANNEGIESSER, H. (1984). CT of bilateral adrenal haemorrhage with acute adrenal insuf- $\bar{D}$ ficiency in the adult. American Journal of Roentgenology, 142, 311.

XARLI, V.P., STEELE, A.A., DAVIS, P.J., BUESCHER, E., RIOS, C.N. \& GARCIA-BUNUEL, R. (1978). Adrenal haemorrhage in the adult. Medicine, 57, 211. 